\title{
碘插人 $\mathrm{Bi}-\mathrm{Sr}-\mathrm{Ca}-\mathrm{Cu}-\mathrm{O}$ 晶体的结构变化
}

周贵恩 黄允兰贾云波 卢近石磊

(中国科学技术大学结构研究开放实验室,合肥 230026)

陈祖耀顾震天 钱透泰 正习清

(中国科学技术大学应用化学系, 合肥 230026)

张裕桓

(中国高等科学技术中心(世界实验室), 北京 100080 ; 中国科学技术大学结构研究开放实验室, 合肥 230026)

关勧词 2212 相单晶、插入碘、X 射线行射、结构变化

\section{一、引盲}

Xiang 崩等报道了碘插人 $\mathrm{Bi}_{2} \mathrm{Sr}_{2} \mathrm{Ca}_{1} \mathrm{Cu}_{2} \mathrm{Oy}$ 高 $T_{\mathrm{c}}$ 超导体的初步物理特征, 原晶体 $c$ 轴为 $30.82 \AA$, 插人碘后的晶体 $c$ 轴变为 $37.78 \AA$. 该文作者认为碘插人晶体后, 在每个 $c$ 周期中增 加了一个 $3.5 \AA$ 厚的碘层. 原晶体的超导转变温度在 $82 \mathrm{~K}$ 到 $90 \mathrm{~K}$ 的范围, 插人碘后的 2212 相晶体除了超导转变范围很窄 $\left(T_{\mathrm{c}}-80 \mathrm{~K}\right)$ 外, 没有发生根本变化. 陈祖耀研究组重复了 Xiang 等人的工作 ${ }^{2}$, 并对 $\mathrm{Bi}$ 系其它相晶体做碘插人研究, 发现 2201 相等晶体也有类似结构 变化. 本文用 $\mathrm{X}$ 射线行射方法研究了碘插人 $\mathrm{Bi}_{2} \mathrm{Sr}_{2} \mathrm{Ca}_{2} \mathrm{Cu}_{2} \mathrm{Oy}$ (简称 2212 相)晶体后的结构变 化. 与原晶体比较, 发现碘插人 2212 相晶体后, 不但 $c$ 轴增加了 $3.5 \AA$ (从c - $15.4 \AA$ 增加到 $18.9 \AA$ ), 而且 $\mathrm{Bi}$ 原子聚集带在 $a 、 b$ 方向周期消失, 而被 $\mathrm{Bi}$ 原子聚集带分割的二维晶格 仍然存在, 只是发生了严重晶格畸变, 不但说明了碘插入后的晶体超导转变温度没有发生根本 变化的原因, 也进一步证明 $\mathrm{Bi}-\mathrm{Sr}-\mathrm{Ca}-\mathrm{Cu}-\mathrm{O}$ 超导体不是通常意义的三维晶体.

\section{二、实验}

实验所用的原晶体是定向凝固法生长的 2212 相单晶”, 尺寸约 $5 \times 3 \times 0.1 \mathrm{~mm}^{3}$. 把原晶 体放人自制的高压容器中, 在 $200^{\circ} \mathrm{C} 、 10$ 个大气压下保持 10 天, 然后冷却至室温。经过 $\mathrm{I}_{2}$ 蒸 汽处理过的样品, 由黑亮变为略带紫色. 扫描电子显微镜作微区分析, 晶体的 (ool) 面上碘均 匀分布, 含量约 $15 \%$ (重量), 垂直 (ool) 面的横截方向磑的分布梯度不大.

$\mathrm{X}$ 射线衍射实验用 $\mathrm{D} / \mathrm{Max}-\mathrm{rA}$ 旋转阳极 $\mathrm{X}$ 射线衍射仪, $\mathrm{Cu}$ 靶, 石墨单色器结合脉冲高 度分析器 (PHA), 衍射几何为 Bragg-Brantano (BB), 得到 (ool) 多级衍射, 劳厄照相和单 色光背反射平板照相用 $\mathrm{JF}-1$ 型 X 射线源, Cu 靶, 点焦点. 单色光平板照相时用 $\mathrm{LiF}$ 单晶 (200) 衍射的窗口单色器, 分光后得到 $\operatorname{CuK\alpha }$ 辐射. 所有衍射照相都是人射光沿 $c$ 轴方向人

本文 1991 年 3 月 25 日收到.

1) 陈祖耀等, 中国物理拄报, 即将发表.

2）䫀根大等, 㫛体生长, 待发表. 
射.

\section{三、结果与讨论}

图 1(a) 和 (b) 分别是衍射仪 BB 几何布置的 2212 相单晶碘插入前后的 (ool) 多级衍射, 给出晶体在 $c$ 方向的周期性. 硒插人前, 2212 相的 $c-15.40 \AA$; 碘插人后 $c$ 周期 变长 $3.5 \AA, c-18.90 \AA$. 图 2(a) 和 (c) 是 2212 相单晶插人碘前后的劳厄衍射花 样. 图 2(b) 是 2212 相单晶(没有插人碘) 的单色光背反射衍射花样, 只有布喇格衍 射层线. 通过它与图 2(a) 比较, 有助于把 图 2(a) 的劳厄衍射和布喇格衍射区分开. 比较碘插人 2212 相前后的 X 射线衍射花 样变化, 可以得到结构变化. 图 2(a) 的衍 射花样由两部分衍射组成, 一部分是过中 心光束放射直线上的斑点, 这些衍射点 是劳厄斑点, 每一条直线上的斑点对应着 晶带大圆的劳厄衍射. 另一部分是单色光 $\mathrm{CuK}_{\alpha}$ 产生的布喇格衍射层线, 在平板照 相时是双曲线，每一条双曲线上的衍射对

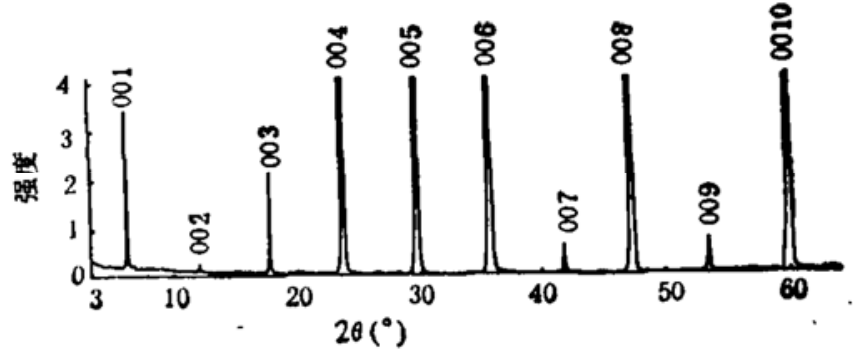

(a)

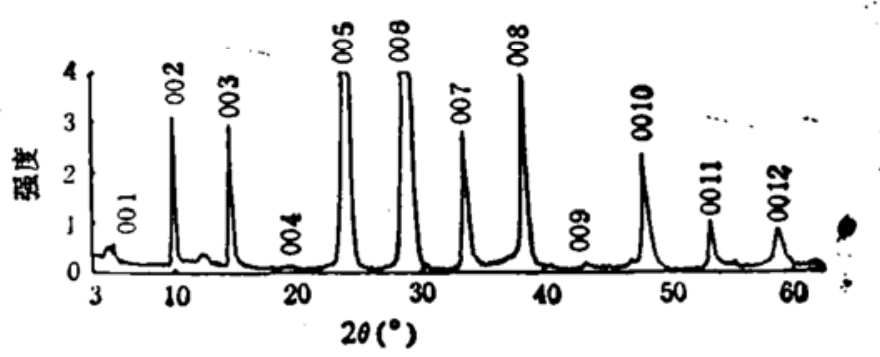

(b)

图 1 插人碘前后的 2212 相单晶的 (001) 多级行射 (a) 没插人磺；（b）插人磷

应着 $b^{*}$ 方向倒易点阵列. 劳厄衍射是由 $\mathrm{Bi}$ 原子聚集带 ${ }^{[2]}$ 分割晶体所形成的大周期, 在理想 情况是三维周期. 单色光 $\mathrm{CuK}_{a}$ 的布喇格衍射层线对应着 $a b$ 面上的二维晶格, 它是 $b$ 方向

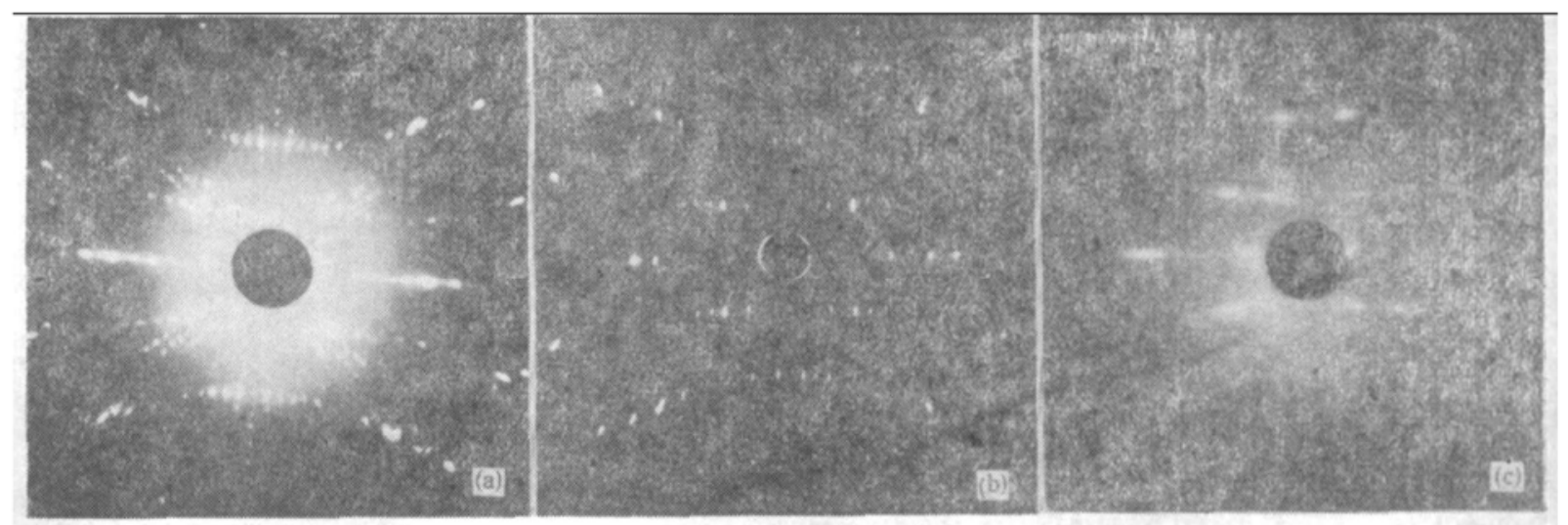

图 22212 相单晶衍射花样

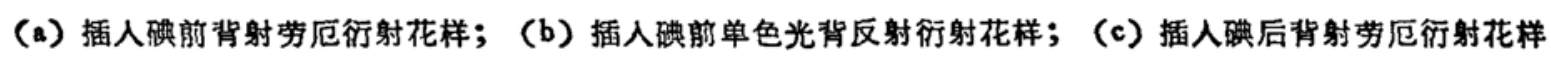

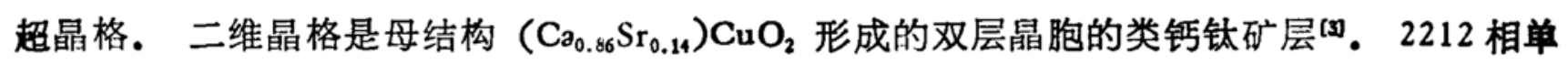
晶是 $\mathrm{Bi}$ 原子聚集带分割母结构(两层晶胞)形成的层状结构.

从碘插人前后多级衍射比较看出, 2212 相单晶插人碘后 $c$ 周期增加了 $3.5 \AA$, 这个值稍 大于母结构晶格常数 $c-3.2 \AA^{[3]}$. 插人碘后结构的这种变化有两种可能, 一种是如文献 [1] 所认为的增加一层磑层; 另一种可能, 插人 $I_{2}$ 后使结构调整, 增加一个母结构晶胞层, Bi 原 子聚集带不是分割两层类钻钛矿准晶咆层, 而是三层. 后种可能可由劳厄照相得到部分说明. 
比较硆插人前后的劳厄照相图 2(a) 和 (c) 可以发现, 插人䃆后, 分布在放射状直线上的劳厄 理点消失,说明 Bi 原子聚集带形成的三维周期珄受到破坏; 布喇格衍射层线还在, 说明晶体 中 $\mathrm{Bi}$ 原子聚集带还在, $\mathrm{Bi}$ 原子聚集带形成的 $c$ 周期还在, 仍然分割晶体形成二维层状堆 积. 值得注意的是, 磧插人后布喇格衍射层线上超点阵斑点已模糊不清, 使层线连成一线, 说 明二维晶格严重畸变,但仍然是 $b$ 方向超点阵.

\section{四、结论}

从上述分析可以得出结论, 碘插人 $\mathrm{Bi}-\mathrm{Sr}-\mathrm{Ca}-\mathrm{Cu}-\mathrm{O}$ 晶体后, 没有改变晶体的二维结构特 征. 改变的只是 $c$ 方向增加一个 $3.5 \AA$ 的层,二维晶格产生严重畸变, $\mathrm{Bi}$ 原子聚集带在 $a b$ 方 向周期基本消失, 从而解释了文献 [1] 中超导电性没有受到破坏的结论, 同时也进一步证明了 Bi 系高温超导体不是通常意义的三维晶体.

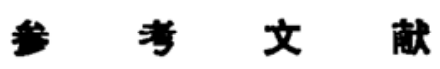

[1.] Xisng, X. D. et al., Nature, 1990, 348: 145.

[2] Matsui, Y. and Moriuchi, S., Jpn. J. Appl. Phys., 27(1988), L2306.

[3] Siegriat, T., Zakurak, S.M., Murphy, D. W. and Roth, R. S., Nature, 1988, 334: 231. 